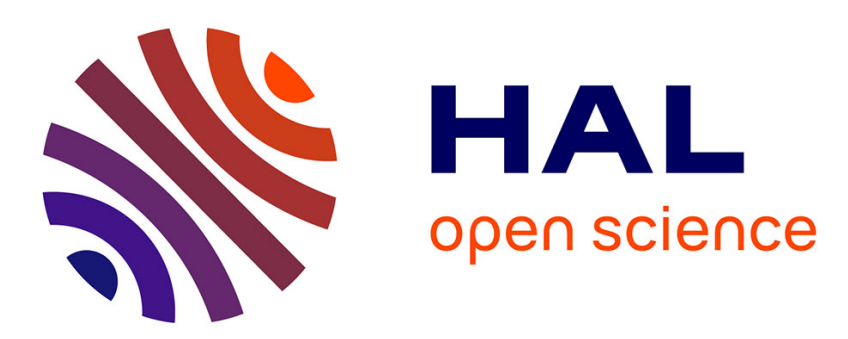

\title{
Innovative technologies for point-of-care testing of viral hepatitis in low-resource and decentralized settings
}

Léa Duchesne, Karine Lacombe

\section{To cite this version:}

Léa Duchesne, Karine Lacombe. Innovative technologies for point-of-care testing of viral hepatitis in low-resource and decentralized settings. Journal of Viral Hepatitis, 2017, 10.1111/jvh.12827 . hal01651784

\section{HAL Id: hal-01651784 \\ https://hal.sorbonne-universite.fr/hal-01651784}

Submitted on 29 Nov 2017

HAL is a multi-disciplinary open access archive for the deposit and dissemination of scientific research documents, whether they are published or not. The documents may come from teaching and research institutions in France or abroad, or from public or private research centers.
L'archive ouverte pluridisciplinaire HAL, est destinée au dépôt et à la diffusion de documents scientifiques de niveau recherche, publiés ou non, émanant des établissements d'enseignement et de recherche français ou étrangers, des laboratoires publics ou privés. 
Innovative technologies for point-of-care testing

of viral hepatitis in low-resource and decentralized settings

Léa Duchesne ${ }^{1,2}$, Karine Lacombe ${ }^{1,2,3}$

1 Sorbonne Universités, UPMC Univ Paris 06

2 Inserm, Institut Pierre Louis d'épidémiologie et de Santé Publique (IPLESP UMRS 1136), Paris,

France

3 Service de maladies infectieuses et tropicales, Hôpital Saint-Antoine, AP-HP, Paris, France

Corresponding author: Léa Duchesne

Inserm UMR-S1136

27 rue Chaligny 75012, Paris, France

e-mail: ljmduchesne@gmail.com

Tel: +33671626677 


\section{ABSTRACT}

According to the Global Burden of Diseases, chronic viral hepatitis B and C are one of the most challenging global health conditions that rank among the first causes of morbidity and mortality worldwide. Low and middle income countries are particularly affected by the health burden associated with HBV or HCV infection. One major gap in efficiently addressing the issue of viral hepatitis is universal screening. However, the costs and chronic lack of human resources for using traditional screening strategies based on serology and molecular biology preclude any scaling-up. Point-of-care tests have been deemed a powerful potential solution to fill the current diagnostics gap in lowresource and decentralized settings. Despite high interest resulting from their development in recent years, very few point-of-care devices have reached the market. Scaling down and automating all testing steps in one single device (e.g. sample preparation, detection and readout) is indeed challenging. But innovations in multiple disciplines such as nanotechnologies, microfluidics, biosensors and synthetic biology have led to the creation of chip-sized laboratory systems called "lab-on-a-chip" devices. This review aims to explain how these innovations can overcome technological barriers that usually arise for each testing step while developing integrated point-of-care tests. Point-of-care test prototypes rarely meet the requirements for mass production, which also hinders their large-scale production. In addition to logistical hurdles, legal and economic constraints specific to the commercialization of in vitro diagnostics, which have also participated in the low transfer of innovative point-of-care tests to the field, are discussed.

Keywords: biosensors, lab-on-a-chip, microfluidics, nanotechnology, point-of-care tests, synthetic biology 


\section{Introduction}

In 2015, the Global Burden of Diseases study has ranked death from chronic viral hepatitis and associated conditions such as cirrhosis and liver cancer among the top 20 causes of death worldwide, with a steep increase between 1990 and 2015 (1). The World Health Organization (WHO) has recently taken steps in tackling the epidemic of hepatitis $B$ and $C$ by issuing guidelines for care and management $(2,3)$ and editing a strong statement towards the global elimination of both epidemics by year 2030 (4). The most affected countries in the fight against viral hepatitis are the low and middle income countries that have combined for years a global political inertia around hepatitis and structural barriers to screening (high costs, extreme centralization of technical and human resources) (5). Indeed, conventional laboratory techniques require continuous access to electricity and water, refrigeration capacities and trained human resources able to perform and interpret complex assays, and are therefore restricted to major cities.

"Point-of-care tests" (POCTs) are portable devices meant to perform diagnostic assays at or near the site of patient care. Due to their small size and their fast time-to-answer, they could bring instantaneous diagnostic and monitoring capacities to decentralized settings. However, to make a real impact, POCTs not only need to be compact but also affordable, sensitive, specific, user-friendly, rapid, equipment-free and delivered to the populations who need them, as summarized in the "ASSURED" criteria created by the WHO (6). Unfortunately, few POCTs currently on the market meet those requirements.

Regarding viral hepatitis diagnosis, the vast majority of commercialized POCTs are lateral flow immunoassays (LFIAs). Although portable and very easy to use, they often lack sensitivity and specificity, which limits their reliability and adoption in the field. The very few POCTs able to perform molecular assays feature bench-top formats that are not adapted to POC contexts because they require a power supply and minimally trained personnel and are expensive.

More generally, POCT development has been hindered by technical difficulties in scaling down, automating and integrating all testing steps-namely sample pre-treatment, amplification if needed, detection and readout of the result for interpretation-into a single "sample-to-answer" device. Research in diagnostics development has focused mainly on miniaturizing and improving sensing mechanisms, resulting in the creation of very sensitive devices that necessitate the addition of bulky external equipment to perform sample preparation or to report test results. However, advances in many different scientific and technological disciplines over the last decade, such as micro and nanomaterials, bio-engineering and microfluidics, have enabled the creation of integrated devices, called lab-on-a-chip (LOC) (7). When applied to clinical diagnostics, these automated laboratories 
miniaturized onto a chip can provide solutions to POCT development barriers and meet the ASSURED criteria.

This review aims to give an overview of the main difficulties encountered for scaling down each testing step and innovative techniques developed to overcome those difficulties in the field of viral hepatitis. Fig. 1 summarizes the main challenges and advances discussed here. In addition to these technical aspects, challenges related to the translation from the laboratory to the field of these technologies are also discussed.

\section{Sample preparation}

Sample preparation ensures the quality of analysis in complex matrix, such as blood or urine, by separating the target analyte from compounds that could cause cross-reactivity or interfere with the detection technique. Since biomarkers are present in particularly low molar concentration, concentration or amplification of the target are also often necessary. Conventional techniques for sample preparation are expensive and time-consuming. Research to simplify and automate sample preparation has lagged considerably compared to the development of sensing mechanisms suitable for POC applications. As a result, it remains one of the major challenges for POCT development.

Microfluidics systems aim to process and manipulate small volume of fluids automatically through specifically designed micro- or nano-channels and compartments. The unique physical and chemical properties presented by fluids at these scales have been exploited to create miniaturized sample preparation devices based on mechanical, chemical and affinity-based techniques (8).

\section{Mechanical techniques}

Separation of the target from the matrix can be performed using mechanical techniques, the most common being centrifugation and filtration. Some ingenious centrifuges based on daily objects, such as an egg beater or a salad spinner (9), were developed to reduce costs, complexity and infrastructure requirements associated with these techniques. Although these devices are a first step to bringing sample preparation to the field, manual manipulations are still needed to transfer the extraction product to the analytical device, thereby increasing contamination risks. Microfluidic centrifugal devices, also known as lab-on-a-CD (LOD) because their microfluidic system is implemented on a rotating disc, can use the pseudo-forces created by the rotation to lyse cells, sort particles or mix fluids, and integrate other functions such as detection (10). Porous membranes made of fluidic components, 
such as pillars or holes, of sizes similar to target analytes can be used to filtrate cells or even single molecules according to their size or density. For example, Sang et al. were able to successfully separate plasma and HIV virus from whole blood samples by means of micrometer-scale pores (11). These filters are precise and easy to manufacture and combine with detection devices but susceptible to clogging. Other systems exploit the hydrodynamic properties of microfluidics to precisely control the flow rate and specifically sort compounds, through precise geometrical design of channels (12).

\section{Chemical techniques}

Sample preparation can also be performed using chemical reagents. Chemical protocols usually involve multiple steps that must be executed in a specific order and with precise timing, which are difficult to automate in miniaturized devices. Chemically modified papers able to collect, store and extract nucleic acids (NAs) from a blood sample have already been commercialized. Although very efficient, most of them still require manual interventions, such as adding reagents or washing steps, which decrease their value for potential POC utilization. The addition and mixing of reagents can be automated by using chambers containing pre-loaded reagents and designed to produce a turbulent flow while the sample flows through it. Droplet-generating microfluidic systems can deliver fluids in a complex, automated and specific sequence (13).

\section{Affinity-based techniques}

Affinity-based mechanisms use a probe immobilized on a surface to specifically capture the target biomarker. As many detection methods also recognize their target by means of a probe, affinity-based separation techniques have great potential to integrate both operations into the same module.

Antibodies are the most broadly used affinity probes, due to their high selectivity and numerous pathogens they can target. However, using them in POCTs presents several drawbacks. First, they have limited stability in environmental conditions common in POC settings, such as extreme temperature. Additionally, antibodies production methods are very well-known but expensive and complex. Similarly, nucleic acid probes fabrication remains expensive. Therefore, alternative affinity tools, such as engineered binding proteins, aptamers or molecular imprinted polymers (MIPs), which are more versatile, cheaper and easier to produce, have been developed (14).

These affinity tools can be combined to nanoparticles (NPs) with magnetic or electric properties when used for electro-kinetics separation. By applying an electric field to the matrix, nanoparticle beads functionalized with an affinity tool can make the targets migrate to a specific area of the device 
for detection. For instance, a magnetic bead-based separation technique integrated into a small microfluidic chip could efficiently separate influenza A virus from whole blood, serum and saliva samples within 15 minutes (15).

\section{Detection}

The detection threshold for many POCTs currently on the market is too high compared to biomarker concentrations in raw samples. Various strategies have been adopted to improve test sensitivity. Firstly, a precise target isolation and concentration step can be implemented, as previously shown. Secondly, the target or its signal can be amplified to reach the low limit of detection (LLOD) of the assay. This process is particularly necessary for NA detection but miniaturizing it has been a major challenge because of its complexity (16). Finally, ensuring the robustness and selectivity while developing sensing methods is crucial to overcome matrix effect.

\section{Nucleic acid amplification-based techniques}

Amplification by polymerase chain reaction (PCR) is the most commonly method used to duplicate small amounts of NA. Based on temperature-dependent reactions, processing PCR requires a thermocycler, a bulky and expensive piece of equipment, to control heating cycles. Mini thermocyclers with rechargeable batteries, such as the miniPCR (17), are now available on the market, or they can be found through open-source projects (18). However, because of their price (between US \$200 and \$650) and need for minimally skilled technicians, they are more suitable for small laboratories than for POC settings. Isothermal amplification methods were developed to reduce the complexity of heat control. However, they still require a minimal heating process and, therefore, a source of energy, a scarcity in low-resource or decentralized settings.

To adapt this need to POC settings, research teams used miniaturized sources of electricity, such as commercial heat packs (19). Others developed electricity-free devices, generating power or heat through chemical reaction or paper-based batteries. For example, the non-instrumented nucleic acid amplification (NINA) platform is a thermos-sized device incorporating a heater, based on an exothermic chemical reaction. The materials necessary to construct the heater are widely available and cost $\$ 0.60$ per test. NINA was easily combined with an HIV lateral flow assay (LFA) and showed performance similar to commercialized PCRs (20). 
Microfluidics' small size enables quick heat transfers, which offer great opportunities in scaling down the PCR process. Although the integration of all the complex NA amplification-based detection steps into one single device remains challenging, advances have been made in this domain (21). However, the costs of primer production and licensing fees associated to the majority of isothermal amplification reactions could hinder the adoption of such technologies for POCTs targeting developing countries.

\section{Micro and nano-scale sensors}

Biosensors are compact sensing devices made of a biological recognition element, immobilized on the surface of a transducer. The transducer converts the physical or chemical variation produced at its surface by the interaction between the recognition element and the target into a measurable or observable reporting signal proportional to the target concentration. Since the whole detection process occurs at once in the same module, without requiring additional steps like reagent addition or washing, biosensors have a fast time-to-answer. In addition, due to their very small size, they can perform with smaller sample volumes than in conventional assays, reducing the quantity of reagents needed and thus lowering assay costs. They have therefore been extensively studied to create POCTs (22). Major impediments to wide adoption of biosensors in POCTs include mixed sensitivity and specificity in raw samples, complexity of production and need for external analyzer to interpret the signal (23).

Biosensors can be classified according to the nature of the reaction their transducer can detect (electrochemical, optical or mechanic) or their detection strategy. Labeled assays work as traditional sandwiched assays where the target is caught between the recognition element and a detector element functionalized with a signalling tag. For label-free assays, the transducer directly senses the changes produced at its surface by the bio-recognition process (24). The detection and signalling properties of a transducer or a tag are determined by the characteristics of the material they are made of. The development of nano-materials with novel signaling properties has enabled the creation of innovative ultra-sensitive detection methods (25). Carbon nanotubes (CNTs), NPs and grapheme have undergone the most study.

Among NPs, gold NPs are a preferred tool for labelling due to its biocompatibility, surface-tovolume ratio and ease to functionalize with biological affinity compounds. In addition, its ability to change color in response to a variation in the environment composition makes it a powerful signal enhancer. The high electron transfer capacities of CNTs and graphene make them able to greatly amplify the detection signal and are therefore effective transducers. For instance, they have been used as electrodes in many biosensor prototypes (26). All these materials can also be coated on the sensing 
surface or inserted inside it to enhance the detection signal (27). Biosensor and nanomaterial-based technologies applied to HBV and HCV detection have been reviewed elsewhere (28-30). Table 1 presents a non-exhaustive list of the most recently developed viral hepatitis biosensors and their characteristics regarding detection and their level of integration in a single device.

Mass spectrometry (MS), although not based on a biological recognition element, is worth mentioning as a potential future micro-sensor for POCTs. Its mechanism, based on the direct identification of molecules or nucleic acid sequences of interest through measurement of their mass after ionization of the sample, could remove the need for sample preparation. Recent advances made to incorporate it into microfluidic structures open up opportunities for miniaturizing MS analysis systems (31).

\section{Synthetic biology-based biosensors}

Synthetic biology aims to reprogram natural mechanisms of biological systems to meet human needs. Yet, many biological systems possess very sensitive machineries to sense environmental changes and adapt their metabolism to them. Therefore, synthetic biology researchers have engineered them to create detection tools.

\section{Synthetic RNA regulators}

Riboregulators are engineered RNAs capable of regulating expression of their own gene or of a target gene, in response to a change in their environment, at the translational or transcriptional level. Thus, they can be used as sensors regulating the expression of a measurable protein to report the presence or the absence of a target RNA. A new design of a translational riboregulator that can be adapted to any target RNA called "toehold switches" was developed (32). Pardee et al. used this technology to construct a sensor able to detect Zika virus RNA in concentrations as little as 3Fm in 30 minutes (33). They created a fast toehold switch-based sensor development protocol, from the design stage to prototype manufacturing, which was completed in 5 days at a very low investment cost (\$20/prototype) and a final cost of $\$ 0.10-\$ 1.00$ per test. Isothermal amplification of NA was necessary to reach clinically relevant sensitivity. Future research about how to combine this technology and simplified amplification techniques will therefore be needed to fashion an operational POCT. Up to now, synthetic biology-based sensing mechanisms could only be engineered in cell-systems, but a technique developed recently has made transcription and translation (TX-TL) reactions in vitro possible (34). This TX-TL system was used to transfer the Zika biosensor onto filter paper. 
RNA regulators acting at the transcriptional level, like the small transcription activating RNAs (STARs), could also be used to detect RNA as well as DNA. However, to our knowledge, this technology has still not been applied to diagnostics.

\section{CRISPR-based biosensor}

The CRISPR/Cas9 is an editing genome tool inspired from a bacterial defense system. CRISPR, the acronym for "clustered regularly interspaced short palindromic repeats," refers to repeated sequences corresponding to viral sequences situated into bacterial genomes. An endonuclease called cas9 uses the translated RNAs from CRISPR sequences to bind and then cut the viral genome. By replacing bacterial CRISPR with synthetic guide RNAs targeting a specific DNA sequence, researchers transformed this system into an editing genome tool. So far, it has been primarily used as molecular scissors to inhibit genes, by shortening them, or to add DNA sequences in a specific locus.

A CRISPR-based nucleic acid detection tool was recently developed, the SHERLOCK ("specific high sensitivity enzymatic reporter unlocking") platform (35), a modified version of CRISPR/Cas9. In this system, CRISPR RNAs were designed to target RNA instead of DNA. It also includes a different ribonuclease, the Cas13a, whose specificity is to cut any nearby RNAs when it binds to its target. Placed in contact with fluorescent RNAs, the CRISPR/Cas13a system can therefore report the presence of a target. Combined with isothermal NA amplification, SHERLOCK detected attomolar $\left(10^{-18}\right)$ concentrations of NA in serum or urine. Moreover, it was specific enough to distinguish virus sequences differing by a single-base mismatch.

\section{Metagenomics}

The vast majority of NA detection techniques require that NA sequences be designed specific to the target. This phase is complex, time-consuming and expensive. Recent advances in metagenomics, a method to directly sequence all NA present in raw samples, could facilitate NA detection. Until now, this technique was too expensive and lengthy to be used in diagnostics. Moreover, data analysis must be conducted with computational software by high-skilled personnel. The decreasing cost and shorter turn-around time of metagenomics have heightened interest in developing and facilitating diagnostic metagenomics-based diagnostics. Thus, Taxonomer, a fast and user-friendly web-based metagenomic sequence analysis tool was developed (36). Furthermore, mobile sequencers are now available. For example, the MinIONs device is the size of a pen drive and was able to read the genome of Ebola viruses from 14 patients in only 48 hours (37). 
Micro-sensors are powerful and versatile solutions to simplify detection. One of the major remaining challenges in designing them is the difficulty in suppressing background noise and intrinsic variability. In addition to increasing selectivity and sensitivity of detection strategies, efforts have been made to create built-in noise correction, by using a ratiometric signal for example (38). Another challenge concerns the conversion of micro-sensors signals into a readable output for the end-user. This process often necessitates expensive and bulky reporting systems sensitive enough to measure a signal in small reaction volumes. An enhanced reporting signal such as those reviewed in this section can help to reduce the inherent complexity of these systems.

\section{Integration}

Ideally, untrained individuals should be able to use POCTs in field settings where sample contamination risks are high. Designing devices able to process all the assay procedures without external manipulations is therefore essential. Yet, most proposed solutions to scale down these different steps have been developed separately, resulting in devices that are very efficient but only address one specific hurdle and lack sufficient compatibility with other devices. This lack of synergy and flexibility limits the potential impact these innovations may have in broadening diagnosis access. The case of viral hepatitis perfectly illustrates this phenomenon. Indeed, as shown in Table 1, although many sensitive innovative and miniaturized sensing mechanisms have been developed for the diagnosis of viral hepatitis, very few of them include all testing steps or are integrated in a fully operational device. However, promising solutions have been developed for other infectious diseases and could be adapted for diagnosis of viral hepatitis.

In recent years, combining microfluidics and biosensors has enabled the creation of on-chip miniaturized laboratory systems called "lab-on-a-chip" (LOC), bringing new opportunities for developing integrated diagnostic devices. The challenges of designing such devices lie not only in integration but also in meeting POCT requirements, namely low-cost and ease of production, process automation and a portable results-reporting system.

\section{Substrates}

Chip material selection is a key step that impacts the complexity of microfluidics networks that can be implemented in the chip, ease of manufacturing and price of the whole LOC. Yet, this must be 
balanced with the need for the material to be compatible with the sample, sensing mode and reagent characteristics. The first microfluidics chips were principally made of glass, silicon and especially polydimethylsiloxane (PDMS), an elastomer. Despite its many advantages for LOC conception-such as transparency, low-cost pilot scale manufacturing and ability to support thin channels and external elements-PDMS-based LOCs have been poorly commercialized due to high costs of large-scale production. Therefore, alternative materials adapted for POCT mass production were investigated, and two candidates appear to be particularly promising: thermoplastics and paper.

Mass production methods using thermoplastics, another kind of polymers, are less expensive than using PDMS and rely on replicating a mold. Producing the molds can be time-consuming, expensive and therefore unsuitable for prototyping, but direct fabrication techniques have been recently developed. Thermoplastics can support many different assays due to its compatibility with a wide variety of chemicals. Moreover, thermoplastic chips allow for the insertion of a high concentration of channels and compartments and thus have the capacity to generate complex designs, such as LODs.

Paper is an attractive choice for large-scale POCT fabrication due to its low-cost, capillarity properties, portability, worldwide availability, well-known manufacturing processes and compatibility with a wide range of chemical and biological components. Moreover, paper can drive fluids by capillarity, removing the need for external pumps or moving parts. Methods to insert channels defined by hydrophilic barriers or to create multiple-layered structures on paper have been developed, giving rise to microfluidic paper-based analytical devices ( $\mu$ PADs) able to support more complex assays than the traditional LFAs or dipstick assays. For instance, plasma separation and simultaneous detection of aspartate aminotransferase and alanine aminotransferase could be accurately performed in serum and whole blood by a three-dimensional (3D) $\mu$ PAD created by stacking patterned paper and wax printing of channels (39). In 15 minutes, it provided a colorimetric output with an intensity proportional to the target concentrations. Such semi-quantitative measurements are common in paper-based assays but are sensitive to intra-rater discrepancies and are not sufficient when precise monitoring is needed. The creation of simple and cost-effective methods to print electrodes on $\mu$ PADs has expanded their use in quantitative analysis of biomarkers. Thus, a microfluidic paper-based electrochemical device ( $\mu P E D)$, tested in mouse serum, was able to detect HIV p24 core antigen and HCV core antigen with limits of detection of $300 \mathrm{pg} / \mathrm{mL}$ and $750 \mathrm{pg} / \mathrm{mL}$, respectively (40).

Many features of POCTs are determined by their substrate, including their potential for large-scale manufacturing. Material selection must therefore be done at the early stages of POCT design while taking into account all the final device requirements. 


\section{Automation}

The first LOCs required external devices for fluid control, sample loading and reagents addition and, therefore, manipulations by the user. To be used as POCTs, LOCs must be automated as much as possible.

To prevent reagent manipulations while testing, printing methods were developed to pre-pattern them in a stabilized form on the chip (41). Since POC settings lack storage or refrigeration capacity, diagnostic tests must be treated in order to ensure long-term conservation of reagents without efficacy loss. Solid or liquid chemicals can be conserved in a solid form by lyophilisation and then rehydrated by the sample itself. Freeze-drying was used to store the Zika toehold switch biosensor on paper, as previously cited (33). Encapsulation of reagents in natural polysaccharide was also developed to store chemicals on chips (42). Storage of reagents in a liquid form, which was a challenge until now, was performed using micro pouches (43) or bio-inert glass ampoules.

Microfluidics systems are used to control fluidic transport through pressure-driven flow generated with pumps or pressure generators. Integration of such equipment directly into the device implies diminishing its portability or creating additional costs for miniaturization. Different chip designs enable equipment-free flow generation. Paper-based assays, for example, draw the sample through capillarity, with no external device. LODs use the various forces created by its rotation to drive flow between its different modules. A vacuum battery, able to suck liquids by releasing a vacuum that is pre-stored in PDMS pouches, was inserted into a fully integrated diagnostic microfluidic device (19). Automation of flow control may also involve the insertion of micro-valves into the device in order to compartmentalize the different operations performed within it. Valves also increase the complexity of manufacturing and therefore raise production costs, making them less desirable for POTC use. Passive valves regulated by fluid flow have been developed to simplify their design and insertion.

\section{End-user interface}

When not visible to the naked eye or when used for quantitative analysis, the signal produced by a sensor must be converted into an interpretable output. Reporting equipment-a microscope or spectrometers, for instance-often adds costs and complexity to test devices, counteracting the advantages of miniaturization.

Cellphones provide a portable, user-friendly and universally available processing unit. Cellphone-based reporting systems have therefore been developed (44). An initial strategy consists of on-site analysis using a cellphone camera and built-in software able to analyze the photo's features. 
This strategy gives an instantaneous result but is limited to assays with a visual output. Additionally, it requires the use of smartphones, which are not available in all countries. Therefore, compact assay analyzers using cellphones to display results were created, usually from open-source hardware called Arduino enabling a low fabrication cost (45). Other strategies are based on off-site analysis where the data collected by the cellphone camera or the analyzer are sent by text or e-mail to a trained operator who sends back an interpretation of the result. In the same vein, automated analysis by a cloud-based software was successfully developed (46). Most of these strategies are designed for a specific kind of analysis and a wireless or Internet network. To overcome these requirements, a team developed a device able to analyze almost any electrochemical reaction that is compatible with any cellphone and network (47).

\section{Open platforms}

Diagnostic tests are usually drawn up anew according to the characteristics of a specific issue. It has been argued that creating reprogrammable basal platforms could save both development costs and time (48). Conception of such platforms is challenging because they must be able to support different samples, reagents and sensing modes.

An initial approach consists of designing devices able to run one specific analytical technique that works across different pathogens or assays. The open polyvalent platforms (OPPs) are bench-top devices conceived so that their instruments and reagents can be provided by different suppliers, allowing thus to reduce test prices through competition. Recently, a real-time PCR OPPs showed great performance in quantifying HBV DNA in the field, even with a generic assay (49). This concept of design versatility has been applied to more portative prototypes. For example, a fully automated and integrated reverse transcription PCR-based device could be easily adapted to different pathogens (bacterial B. cereus, HIV) just by changing the reagents loaded in the chip (50).

A second approach aims to create fluidic platforms whose design can be tailored to any type of analysis. Based on this idea, a design protocol for a programmable chemistry LOC, inspired by a music box, intended for resource-limited settings was recently published (51). It combines a silicon microfluidic chip containing reagents to a hand-cranked spinning wheel with pins on a punch card. When a pin hits a hole, pumps or valves are activated in the chip, releasing droplets of fluids that were previously loaded onto the chip. Cards can be punched to create particular fluid delivery patterns. The silicon chip can also be modified to hold a specific number of reagent or mixing chambers. The chip is made of inexpensive materials (less than $\$ 5$ overall) and can be re-used after washing and refilling of reagents. 
Using basal platform designs could enable the creation of standards in LOC-based POCT production, which have been pointed out as a potential leverage for scaling up their commercialization (52). However, standardization can also be considered as a drag on innovation. Continuing research is essential and, as there is still no one-size-fits-all POCT design, using a model such as these could prevent teams from having to start from scratch and ease the creation process of integrated devices.

\section{Translation of micro-diagnostics to clinics}

Despite the clear added value LOCs offer in overcoming current POCT limitations, their translation from research laboratories to concrete production and adoption in the field have been almost inexistent in the last decade.

The gap between research objectives and the requirements of the industrialization process, identified as one of the greatest bottlenecks to translation, is gradually closing. Manufacturing includes four major steps: design, fabrication, back-end processes and quality control. Regarding the design phase, LOC technologies have developed and now possess a range of tools broad enough to overcome almost any technical challenge. Additionally, awareness of the need to design devices from the very start that encapsulate all testing functionalities and have easy and low-cost assembly is rising. Although back-end processes and quality control only account for $20 \%$ of prototype production costs, these costs can reach up to $80 \%$ during mass production (53). However, most proof-of-concept published today does not consider this difference. Substrate, sensor and design selection should be carefully considered to minimize device-to-device variability and ease reproducibility. But grants for "basic research" provide little incentive to develop such practical applications. Involving researchers in management sciences and process engineering when developing LOC-based POCTs could ensure appropriate design and simultaneously broaden the number of potential funding resources. Moreover, Sackmann et al. highlighted that LOC studies are published primarily in engineering journals and therefore do not reach clinicians or biologists, although they are the most likely potential end-users (54). To ensure future clinical adoption, information about such technologies should be made more widely available to clinical laboratories and practitioners, who can even participate in the design and evaluation process.

Prior to their commercialization, "in vitro diagnostics" (IVD) must undergo a regulatory approval process in each country where the device will be marketed. Although these processes aim to ensure public safety, their pathways are generally burdensome, opaque and variable between countries. In most cases, National Regulatory Authorities (NRAs) request trials to be conducted in the field to prove the device's efficiency and relevance in application contexts. Such studies require 
substantial funding and also access to local clinical infrastructures. Complexity, duplication of proofs, costs, lack of harmonization and delayed market access may discourage potential investors from commercializing their product in all potential countries of application and contribute to limiting the availability of diagnostics worldwide. Initiatives have been launched to streamline harmonization of regulatory processes for various geopolitical scales, such as the International Medical Device Regulators Forum and the regional Harmonization Working Parties in Africa, Latin America and Asia (55). Similar organisms created to enhance harmonization of drug regulations yielded promising results, such as the harmonized medicines registration system established by the East African Community (EAC) (56). On the other hand, the WHO found that only $58 \%$ of its members possess legal procedures for IVD approval and that the majority of them are incomplete (57). Most countries lack the capacity to apply them, with consequent high levels of poor-quality diagnostics and public health implications. Regional organization of IVD regulations could prevent developers from duplicating trials and enable countries to share their resources.

While POCTs for LRS must be low-cost, their development requires substantial initial investment. Therefore, depending on the market size, return on investment might be low. As a result, POCTs are considered a risky market and lead investors to wait for a "killer application" involving lower risk investments to emerge, although the existence of such an application for LOC-based diagnostics has been questioned (58). This situation has raised the issue of alternative business strategies for POCT marketing. For instance, Diagnostics For All (DFA), a non-profit research company that can receive academic or foundation grants, has partnered with a for-profit subsidiary firm, Paper Diagnostics, which licenses DFA innovations, giving DFA a stable source of revenue through royalties (59).

Beyond technical barriers, for which solutions are increasingly coming, translating POCTs to the field is now principally hindered by the lack of links between the different worlds involved in POCT development. Multidisciplinary collaboration, including basic researchers, clinicians, management and industry sciences from the very beginning, should therefore be strengthened to accelerate and ease POCT adoption in the field. 


\section{Disclosures}

Authors have no conflict of interest to declare.

\section{Abbreviations}

\begin{tabular}{|c|c|}
\hline CNTs & Carbon Nanotubes \\
\hline CRISPR & Clustered Regularly Interspaced Short Palindromic Repeats \\
\hline DFA & Diagnostics for All \\
\hline EAC & East African Community \\
\hline HBV & Hepatitis B Virus \\
\hline $\mathrm{HCV}$ & Hepatitis C virus \\
\hline IVD & In Vitro Diagnostics \\
\hline LFA & Lateral Flow Assay \\
\hline LFIA & Lateral Flow Immunoassay \\
\hline LLOD & Low Limit of Detection \\
\hline LOC & Lab-on-a-chip \\
\hline LOD & Lab-on-a-CD \\
\hline$\mu P A D s$ & Microfluidic Paper-based Analytical Devices \\
\hline$\mu$ PED & Microfluidic Paper-based Electrochemical Device \\
\hline MIPs & Molecular Imprinted Polymers \\
\hline MS & Mass Spectrometry \\
\hline NRAs & National Regulatory Authorities \\
\hline NINA & Non-Instrumented Nucleic Acid Amplification \\
\hline NA & Nucleic Acid \\
\hline NPs & Nanoparticles \\
\hline PCR & Polymerase Chain Reaction \\
\hline PDMS & Polydimethylsiloxane \\
\hline POC & Point-of-care \\
\hline POCTs & Point-of-care Tests \\
\hline STARs & Small Transcription Activating RNAs \\
\hline SHERLOCK & Specific High Sensitivity Enzymatic Reporter Unlocking \\
\hline $\mathrm{TX}$ & Transcription \\
\hline TL & Translation \\
\hline WHO & World Health Organization \\
\hline
\end{tabular}




\section{References}

1. Stanaway JD, Flaxman AD, Naghavi M, Fitzmaurice C, Vos T, Abubakar I, et al. The global burden of viral hepatitis from 1990 to 2013: findings from the Global Burden of Disease Study 2013. Lancet Lond Engl. 2016 Sep 10;388(10049):1081-8.

2. WHO | Guidelines for the screening, care and treatment of persons with chronic hepatitis $C$ infection [Internet]. [cited 2016 Aug 9]. Available at:

http://www.who.int/hepatitis/publications/hepatitis-c-guidelines-2016/en/

3. WHO | Guidelines for the prevention, care and treatment of persons with chronic hepatitis B infection [Internet]. [cited 2017 Aug 3]. Available at:

http://www.who.int/hiv/pub/hepatitis/hepatitis-b-guidelines/en/

4. WHO | Global hepatitis report, 2017 [Internet]. WHO. [cited 2017 Aug 3]. Available at: http://www.who.int/hepatitis/publications/global-hepatitis-report2017/en/

5. Lemoine $M$, Eholié $S$, Lacombe $K$. Reducing the neglected burden of viral hepatitis in Africa: strategies for a global approach. J Hepatol. 2015 Feb;62(2):469-76.

6. TDR | Mapping the landscape of diagnostics for sexually transmitted infections [Internet]. WHO. [cited 2017 Aug 3]. Available at: http://www.who.int/tdr/publications/tdr-researchpublications/mapping-landscape-sti/en/

7. Streets AM, Huang Y. Chip in a lab: Microfluidics for next generation life science research. Biomicrofluidics. 2013 Jan;7(1):11302.

8. Cui F, Rhee M, Singh A, Tripathi A. Microfluidic Sample Preparation for Medical Diagnostics. Annu Rev Biomed Eng. 2015;17(1):267-86.

9. Brown J, Theis L, Kerr L, Zakhidova N, O'Connor K, Uthman M, et al. A Hand-Powered, Portable, Low-Cost Centrifuge for Diagnosing Anemia in Low-Resource Settings. Am J Trop Med Hyg. 2011 Aug 1;85(2):327-32.

10. Kong LX, Perebikovsky A, Moebius J, Kulinsky L, Madou M. Lab-on-a-CD: A Fully Integrated Molecular Diagnostic System. J Lab Autom. 2016 Jun;21(3):323-55.

11. Wang S, Sarenac D, Chen MH, Huang S-H, Giguel FF, Kuritzkes DR, et al. Simple filter microchip for rapid separation of plasma and viruses from whole blood. Int J Nanomedicine. 2012;7:501928.

12. Karimi A, Yazdi S, Ardekani AM. Hydrodynamic mechanisms of cell and particle trapping in microfluidics. Biomicrofluidics [Internet]. 2013 Apr 5 [cited 2017 Jun 24];7(2). Available at: http://www.ncbi.nlm.nih.gov/pmc/articles/PMC3631262/

13. Tian T, Li J, Song Y, Zhou L, Zhu Z, Yang CJ. Distance-based microfluidic quantitative detection methods for point-of-care testing. Lab Chip. 2016 Apr 7;16(7):1139-51.

14. Ruigrok VJB, Levisson $M$, Eppink MHM, Smidt $\mathrm{H}$, van der Oost J. Alternative affinity tools: more attractive than antibodies? Biochem J. 2011 May 15;436(1):1-13. 
15. Lien K-Y, Hung L-Y, Huang T-B, Tsai Y-C, Lei H-Y, Lee G-B. Rapid detection of influenza A virus infection utilizing an immunomagnetic bead-based microfluidic system. Biosens Bioelectron. 2011 May 15;26(9):3900-7.

16. Wu J, Kodzius R, Cao W, Wen W. Extraction, amplification and detection of DNA in microfluidic chip-based assays. Microchim Acta. 2014 Oct 1;181(13-14):1611-31.

17. Guevara EE, Frankel DC, Ranaivonasy J, Richard AF, Ratsirarson J, Lawler RR, et al. A simple, economical protocol for DNA extraction and amplification where there is no lab. Conserv Genet Resour. 2017 Apr 27;1-7.

18. BHA_Thermocycler: Thermocycler for PCR [Internet]. BioHack Academy; 2017 [cited 2017 Jun 24]. Available at: https://github.com/BioHackAcademy/BHA_Thermocycler

19. Yeh E-C, Fu C-C, Hu L, Thakur R, Feng J, Lee LP. Self-powered integrated microfluidic point-of-care low-cost enabling (SIMPLE) chip. Sci Adv. 2017 Mar 1;3(3):e1501645.

20. LaBarre P, Hawkins KR, Gerlach J, Wilmoth J, Beddoe A, Singleton J, et al. A Simple, Inexpensive Device for Nucleic Acid Amplification without Electricity-Toward Instrument-Free Molecular Diagnostics in Low-Resource Settings. PLOS ONE. 2011 May;6(5):e19738.

21. Su W, Gao X, Jiang L, Qin J. Microfluidic platform towards point-of-care diagnostics in infectious diseases. J Chromatogr A. 2015 Jan 16;1377:13-26.

22. Bhalla N, Jolly P, Formisano N, Estrela P. Introduction to biosensors. Essays Biochem. 2016 Jun 30;60(1):1-8.

23. Vigneshvar S, Sudhakumari CC, Senthilkumaran B, Prakash H. Recent Advances in Biosensor Technology for Potential Applications - An Overview. Front Bioeng Biotechnol. 2016;4:11.

24. Luka G, Ahmadi A, Najjaran H, Alocilja E, DeRosa M, Wolthers K, et al. Microfluidics Integrated Biosensors: A Leading Technology towards Lab-on-a-Chip and Sensing Applications. Sensors. 2015 Dec 1;15(12):30011-31.

25. Sang $S$, Wang $Y$, Feng $Q$, Wei $Y$, Ji J, Zhang W. Progress of new label-free techniques for biosensors: a review. Crit Rev Biotechnol. 2016;36(3):465-81.

26. Syedmoradi L, Daneshpour M, Alvandipour M, Gomez FA, Hajghassem H, Omidfar K. Point of care testing: The impact of nanotechnology. Biosens Bioelectron. 2017 Jan 15;87:373-87.

27. Wei F, Lillehoj PB, Ho C-M. DNA diagnostics: nanotechnology-enhanced electrochemical detection of nucleic acids. Pediatr Res. 2010 May;67(5):458-68.

28. Yao C-Y, Fu W-L. Biosensors for hepatitis B virus detection. World J Gastroenterol. 2014 Sep 21;20(35):12485-92.

29. Uliana CV, Riccardi CS, Yamanaka H. Diagnostic tests for hepatitis C: recent trends in electrochemical immunosensor and genosensor analysis. World J Gastroenterol. 2014 Nov 14;20(42):15476-91.

30. Yildiz UH, Inci F, Wang S, Toy M, Tekin HC, Javaid A, et al. Recent advances in micro/nanotechnologies for global control of hepatitis B infection. Biotechnol Adv. 2015 Feb;33(1):178-90. 
31. Wang X, Yi L, Mukhitov N, Schrell AM, Dhumpa R, Roper MG. Microfluidics-to-mass spectrometry: a review of coupling methods and applications. J Chromatogr A. 2015 Feb 20;1382:98-116.

32. Green AA, Silver PA, Collins JJ, Yin P. Toehold switches: de-novo-designed regulators of gene expression. Cell. 2014 Nov 6;159(4):925-39.

33. Pardee K, Green AA, Takahashi MK, Braff D, Lambert G, Lee JW, et al. Rapid, Low-Cost Detection of Zika Virus Using Programmable Biomolecular Components. Cell. 2016 May 19;165(5):1255-66.

34. Shin J, Noireaux V. An E. coli cell-free expression toolbox: application to synthetic gene circuits and artificial cells. ACS Synth Biol. 2012 Jan 20;1(1):29-41.

35. Gootenberg JS, Abudayyeh OO, Lee JW, Essletzbichler P, Dy AJ, Joung J, et al. Nucleic acid detection with CRISPR-Cas13a/C2c2. Science. 2017 Apr 28;356(6336):438-42.

36. Flygare S, Simmon K, Miller C, Qiao Y, Kennedy B, Di Sera T, et al. Taxonomer: an interactive metagenomics analysis portal for universal pathogen detection and host mRNA expression profiling. Genome Biol. 2016;17(1):111.

37. Check Hayden E. Pint-sized DNA sequencer impresses first users. Nature. 2015 May 7;521(7550):15-6.

38. Jin H, Gui R, Yu J, Lv W, Wang Z. Fabrication strategies, sensing modes and analytical applications of ratiometric electrochemical biosensors. Biosens Bioelectron. 2017 May 15;91:523-37.

39. Pollock NR, Rolland JP, Kumar S, Beattie PD, Jain S, Noubary F, et al. A paper-based multiplexed transaminase test for low-cost, point-of-care liver function testing. Sci Transl Med. 2012 Sep 19;4(152):152ra129.

40. Zhao C, Liu X. A portable paper-based microfluidic platform for multiplexed electrochemical detection of human immunodeficiency virus and hepatitis $C$ virus antibodies in serum. Biomicrofluidics. 2016 Mar 1;10(2):024119.

41. Byrnes S, Thiessen G, Fu E. Progress in the development of paper-based diagnostics for lowresource point-of-care settings. Bioanalysis. 2013 Nov;5(22):2821-36.

42. Jahanshahi-Anbuhi S, Pennings K, Leung V, Liu M, Carrasquilla C, Kannan B, et al. Pullulan encapsulation of labile biomolecules to give stable bioassay tablets. Angew Chem Int Ed Engl. 2014 Jun 10;53(24):6155-8.

43. Mauk MG, Liu C, Qiu X, Chen D, Song J, Bau HH. Microfluidic 'Pouch' Chips for Immunoassays and Nucleic Acid Amplification Tests. Methods Mol Biol Clifton NJ. 2017;1572:467-88.

44. Lopez-Barbosa N, Gamarra JD, Osma JF. The future point-of-care detection of disease and its data capture and handling. Anal Bioanal Chem. 2016 Apr;408(11):2827-37.

45. Grinias JP, Whitfield JT, Guetschow ED, Kennedy RT. An Inexpensive, Open-Source USB Arduino Data Acquisition Device for Chemical Instrumentation. J Chem Educ. 2016 Jul 12;93(7):1316-9.

46. Selck DA, Karymov MA, Sun B, Ismagilov RF. Increased Robustness of Single-Molecule Counting with Microfluidics, Digital Isothermal Amplification, and a Mobile Phone versus Real-Time Kinetic Measurements. Anal Chem. 2013 Nov 19;85(22):11129-36. 
47. Nemiroski A, Christodouleas DC, Hennek JW, Kumar AA, Maxwell EJ, Fernández-Abedul MT, et al. Universal mobile electrochemical detector designed for use in resource-limited applications.

Proc Natl Acad Sci U S A. 2014 Aug 19;111(33):11984-9.

48. Patou F, AlZahra'a Alatraktchi F, Kjægaard C, Dimaki M, Madsen J, Svendsen WE. Evolvable Smartphone-Based Platforms for Point-of-Care In-Vitro Diagnostics Applications. Diagn Basel Switz. 2016 Sep 3;6(3).

49. Kania D, Rouet F, Bollore K, Nouhin J, Njouom R, Toni Td'A, Maiga A, Toure-Kane C, Ngo-GiangHuong N, Dagnra A, Chuong Le DH, Lunel-Fabiani F, Chaix M-L, Castera-Guy J, Da Costa Castro J$M$, Rouzioux C, Plantier J-C, Tuaillon E. Validation and scale-up of Hepatitis B viral load on polyvalent open PCR platforms in West African and South East Asian countries. A study of the AC12 working group (ANRS 12327). Poster TUPEB0391. 9th IAS Conference on HIV Science (IAS 2017); 2017 Jul 23-26; Paris, France.

50. Chen D, Mauk M, Qiu X, Liu C, Kim J, Ramprasad S, et al. An integrated, self-contained microfluidic cassette for isolation, amplification, and detection of nucleic acids. Biomed Microdevices. 2010 Aug;12(4):705-19.

51. Korir G, Prakash M. Punch card programmable microfluidics. PloS One. 2015;10(3):e0115993.

52. Mohammed MI, Haswell S, Gibson I. Lab-on-a-chip or Chip-in-a-lab: Challenges of Commercialization Lost in Translation. Procedia Technol. 2015 Jan 1;20:54-9.

53. Becker H. It's the economy.. Lab Chip. 2009 Oct 7;9(19):2759-62.

54. Sackmann EK, Fulton AL, Beebe DJ. The present and future role of microfluidics in biomedical research. Nature. 2014 Mar 13;507(7491):181-9.

55. McNerney R. Diagnostics for Developing Countries. Diagn Basel Switz. 2015 May 19;5(2):200-9.

56. Rugera SP, McNerney R, Poon AK, Akimana G, Mariki RF, Kajumbula H, et al. Regulation of medical diagnostics and medical devices in the East African community partner states. BMC Health Serv Res. 2014 Oct 31;14:524.

57. WHO | Regulations [Internet]. WHO. [cited 2017 Jun 24]. Available at: http://www.who.int/medical_devices/safety/en/

58. Caicedo HH, Brady ST. Microfluidics: The Challenge Is to Bridge the Gap Instead of Looking for a 'Killer App'. Trends Biotechnol. 2016 Jan 1;34(1):1-3.

59. Mace $C R$, Ryan US. A unique approach to business strategy as a means to enable change in global healthcare: a case study. Clin Chem. 2012 Sep;58(9):1302-5.

60. Li X, Scida K, Crooks RM. Detection of Hepatitis B Virus DNA with a Paper Electrochemical Sensor. Anal Chem. 2015 Sep 1;87(17):9009-15.

61. Chen C-C, Lai Z-L, Wang G-J, Wu C-Y. Polymerase chain reaction-free detection of hepatitis B virus DNA using a nanostructured impedance biosensor. Biosens Bioelectron. $2016 \mathrm{Mar}$ $15 ; 77: 603-8$. 
62. Gao Y, Deng X, Wen W, Zhang X, Wang S. Ultrasensitive paper based nucleic acid detection realized by three-dimensional DNA-AuNPs network amplification. Biosens Bioelectron. 2017 Jun 15;92:529-35.

63. Mao X, Liu S, Yang C, Liu F, Wang K, Chen G. Colorimetric detection of hepatitis B virus (HBV) DNA based on DNA-templated copper nanoclusters. Anal Chim Acta. 2016 Feb 25;909:101-8.

64. Mashhadizadeh MH, Talemi RP. Synergistic effect of magnetite and gold nanoparticles onto the response of a label-free impedimetric hepatitis B virus DNA biosensor. Mater Sci Eng C Mater Biol Appl. 2016 Feb;59:773-81.

65. Riedel T, Surman F, Hageneder S, Pop-Georgievski O, Noehammer C, Hofner M, et al. Hepatitis B plasmonic biosensor for the analysis of clinical serum samples. Biosens Bioelectron. $2016 \mathrm{Nov}$ 15;85:272-9.

66. Shawky SM, Awad AM, Allam W, Alkordi MH, El-Khamisy SF. Gold aggregating gold: A novel nanoparticle biosensor approach for the direct quantification of hepatitis $C$ virus RNA in clinical samples. Biosens Bioelectron. 2017 Jun 15;92:349-56.

67. Wang K, Fan D, Liu Y, Dong S. Cascaded multiple amplification strategy for ultrasensitive detection of HIV/HCV virus DNA. Biosens Bioelectron. 2017 Jan 15;87:116-21.

68. Lee J-H, Seo HS, Kwon J-H, Kim H-T, Kwon KC, Sim SJ, et al. Multiplex diagnosis of viral infectious diseases (AIDS, hepatitis $C$, and hepatitis A) based on point of care lateral flow assay using engineered proteinticles. Biosens Bioelectron. 2015 Jul 15;69:213-25.

69. Yang B, Gong H, Chen C, Chen X, Cai C. A virus resonance light scattering sensor based on musselinspired molecularly imprinted polymers for high sensitive and high selective detection of Hepatitis A Virus. Biosens Bioelectron. 2017 Jan 15;87:679-85. 
Table 1. Recent developments on viral hepatitis biosensors

\begin{tabular}{|c|c|c|c|c|c|c|c|}
\hline $\begin{array}{l}\text { Recognition } \\
\text { element }\end{array}$ & Target labelling & $\begin{array}{c}\text { Sample } \\
\text { preparation }\end{array}$ & $\begin{array}{c}\text { Target } \\
\text { amplification }\end{array}$ & $\begin{array}{l}\text { Detection } \\
\text { technique }\end{array}$ & $\begin{array}{l}\text { Device } \\
\text { design }\end{array}$ & Performance & Ref. \\
\hline $\begin{array}{c}\text { HBV DNA } \\
\text { probe-coated } \\
\text { M } \mu \mathrm{Bs}\end{array}$ & Silver NPs & $\begin{array}{l}\text { External mixing } \\
\text { with label and } \\
\text { capture probe }\end{array}$ & No & $\begin{array}{l}\text { Anodic stripping } \\
\text { voltammetry }\end{array}$ & PAD & $\begin{array}{l}\text { LLOD: } 85 \mathrm{pM} \\
5 \mathrm{~min}\end{array}$ & (60) \\
\hline $\begin{array}{l}\text { HBV ssDNA } \\
\text { probe }\end{array}$ & Label-free & $\begin{array}{l}\text { External DNA } \\
\text { purification }\end{array}$ & No & $\begin{array}{l}\text { Electrochemical } \\
\text { impedance } \\
\text { spectroscopy }\end{array}$ & $\mathrm{NI}$ & LLOD: 111 copies/mL & (61) \\
\hline HBV DNA probe & $\begin{array}{l}\text { Streptavidin- } \\
\text { coated gold NPs }\end{array}$ & $\begin{array}{l}\text { External incubation } \\
\text { and mixing }\end{array}$ & No & $\begin{array}{c}\text { Optical } \\
\text { (colorimetric) }\end{array}$ & LFA & LLOD: 0.01 pM & (62) \\
\hline $\begin{array}{l}\text { HBV ssDNA } \\
\text { probe }\end{array}$ & $\begin{array}{c}\text { Copper } \\
\text { nanoclusters }\end{array}$ & $\begin{array}{l}\text { External serum } \\
\text { separation }\end{array}$ & No & $\begin{array}{c}\text { Optical } \\
\text { (colorimetric) }\end{array}$ & $\mathrm{NI}$ & LLOD: $12 \times 10^{9}$ DNA molecules & (63) \\
\hline $\begin{array}{l}\text { Thiolated HBV } \\
\text { DNA probe }\end{array}$ & Label-free & $\begin{array}{c}\text { External plasma } \\
\text { separation and } \\
\text { protein } \\
\text { precipitation }\end{array}$ & No & $\begin{array}{l}\text { Electrochemical } \\
\text { impedance } \\
\text { spectroscopy }\end{array}$ & $\mathrm{NI}$ & LLOD: $3.1 \times 10^{-13} \mathrm{M}$ & (64) \\
\hline $\mathrm{HBsAg}$ & Label-free & $\begin{array}{l}\text { External serum } \\
\text { separation }\end{array}$ & No & $\begin{array}{l}\text { Optical } \\
\text { (surface } \\
\text { plasmon } \\
\text { resonance) }\end{array}$ & $\begin{array}{l}\text { Gold-coated } \\
\text { glass slides }\end{array}$ & $\begin{array}{l}\text { Linear range }>\text { to ELISA range } \\
(0.002-1 \mathrm{IU} / \mathrm{mL}) \\
10 \mathrm{~min}\end{array}$ & (65) \\
\hline
\end{tabular}




\begin{tabular}{|c|c|c|c|c|c|c|c|}
\hline $\begin{array}{l}\text { Recognition } \\
\text { element }\end{array}$ & Target labelling & $\begin{array}{c}\text { Sample } \\
\text { preparation }\end{array}$ & $\begin{array}{c}\text { Target } \\
\text { amplification }\end{array}$ & $\begin{array}{l}\text { Detection } \\
\text { technique }\end{array}$ & $\begin{array}{l}\text { Device } \\
\text { design }\end{array}$ & Performance & Ref. \\
\hline HCV RNA probe & $\begin{array}{l}\text { Citrate-coated } \\
\text { gold NPs }\end{array}$ & $\begin{array}{l}\text { External RNA } \\
\text { extraction }\end{array}$ & No & $\begin{array}{c}\text { Optical } \\
\text { (colorimetric) }\end{array}$ & $\mathrm{NI}$ & $\begin{array}{c}\text { Se: } 93.3 \% \\
\text { Sp: } 100 \% \\
\text { LLOD: } 4.57 \mathrm{IU} / \mu \mathrm{L} \\
30 \mathrm{~min}\end{array}$ & (66) \\
\hline $\begin{array}{l}\text { HCV cAg } \\
\text { HIV p24 cAg }\end{array}$ & $\begin{array}{l}\text { Alkaline } \\
\text { phosphatase- } \\
\text { labeled IgG }\end{array}$ & $\begin{array}{l}\text { External serum } \\
\text { separation }\end{array}$ & No & $\begin{array}{l}\text { Electrochemical } \\
\text { (CV, LSV, CA, } \\
\text { SWV) }\end{array}$ & $\mu \mathrm{PED}$ & $\begin{array}{l}\text { LLOD HIV: } 300 \mathrm{pg} / \mathrm{mL} \\
\text { LLOD HCV: } 750 \mathrm{pg} / \mathrm{mL} \\
20 \mathrm{~min}\end{array}$ & (40) \\
\hline $\begin{array}{l}\text { HIV and HCV } \\
\text { DNA probes }\end{array}$ & Label-free & $\begin{array}{l}\text { External serum } \\
\text { separation }\end{array}$ & CMAS & $\begin{array}{c}\text { Optical } \\
\text { (colorimetric } \\
\text { and fluorescent) }\end{array}$ & $\mathrm{NI}$ & $\begin{array}{l}\text { Fluorescence and colorimetric } \\
\text { LLOD: } 10 \mathrm{fM} \text { and } 0.5 \mathrm{pM}\end{array}$ & (67) \\
\hline $\begin{array}{l}\text { HIV, HCV, HAV } \\
\text { engineered } \\
\text { proteinticle- } \\
\text { based 3D } \\
\text { probes }\end{array}$ & $\begin{array}{c}\text { Protein A- } \\
\text { conjugated gold } \\
\text { NPs }\end{array}$ & $\begin{array}{l}\text { External serum } \\
\text { separation and } \\
\text { mixing with } \\
\text { developing solution }\end{array}$ & No & $\begin{array}{c}\text { Optical } \\
\text { (colorimetric) }\end{array}$ & LFA & $\begin{array}{l}\text { Se: } 100 \% \\
\text { Sp: } 100 \%\end{array}$ & (68) \\
\hline $\begin{array}{c}\text { PD- coated } \\
\text { Hepatitis A virus } \\
\text { MIP }\end{array}$ & Label-free & $\begin{array}{l}\text { External serum } \\
\text { separation }\end{array}$ & No & $\begin{array}{l}\text { Optical } \\
\text { Resonance light } \\
\text { scattering }\end{array}$ & $\mathrm{NI}$ & LLOD: $8.6 \mathrm{pmol} \cdot \mathrm{L}^{-1}$ & (69) \\
\hline
\end{tabular}

HBV: hepatitis B virus, M $\mu B s$ : magnetic microbeads, NI: not integrated in a device, NPs: nanoparticules, PAD: paper analytical device, LLOD: low limit of detection, ssDNA: single strand DNA, , LFA: lateral flow assay, HBsAg: HBs antigen, ELISA: enzyme-linked immunosorbent assay, cAg: core antigen, IgG: immunoglobulin G, CV: cyclic voltammetry, LSV: linear sweeping voltammetry, CA: chrono-amperometry, SWV: square wave voltammetry, $\mu$ PED : Microfluidic Paper-based Electrochemical Device, CMAS : Cascaded multiple amplification strategy, HIV: human immunodeficiency virus, HCV: hepatitis C virus, HAV: hepatitis A virus, Se : sensitivity, Sp : specificity, PD: polydopamin 


\section{Figure legends}

Fig. 1. Overview of the solutions provided by micro and nano-technologies, microfluidics and bio-engineering to the challenges in designing integrated pointof-care tests.

MIPs: Molecular Imprinted Polymers, LOD: lab-on-a-CD, STARs: Small Transcription Activating RNAs, CRISPR: Clustered Regularly Interspaced Short Palindromic Repeats, $\mu$ PADs: Microfluidic Paper-based Analytical Devices, POCT: point-of-care test 


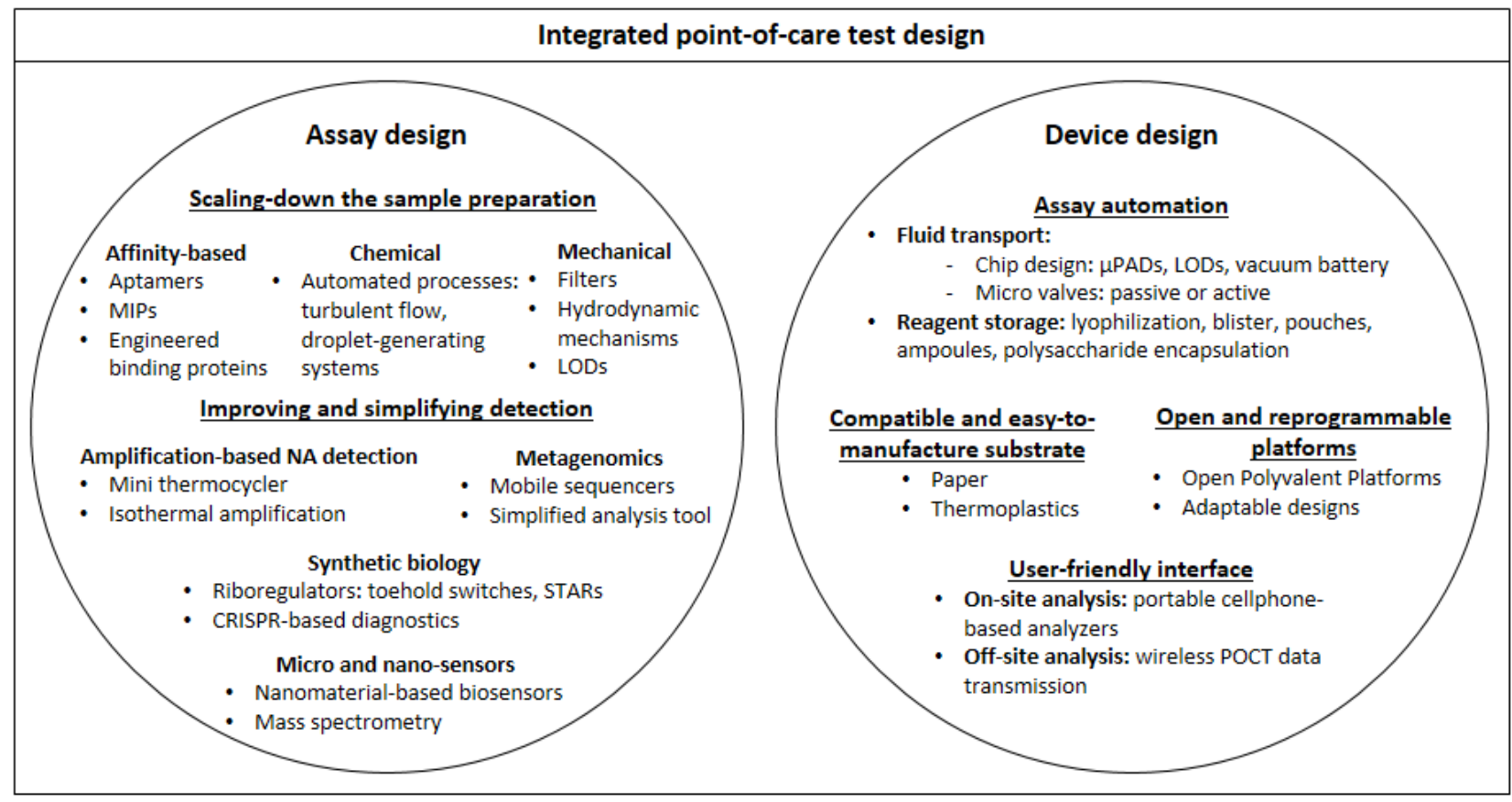

\begin{tabular}{l} 
Challenges \\
$\begin{array}{c}\text { Translation from } \\
\text { research laboratories } \\
\text { to clinics }\end{array}$ \\
$\begin{array}{l}\text { - Multidisciplinary collaboration } \\
\text { - Transition from prototype production to mass production } \\
\text { appromplexity and lack of harmonization in regulatory } \\
\text { - Economic viability }\end{array}$ \\
\hline
\end{tabular}

